\title{
Round Epithelial Cell Count
}

National Cancer Institute

\section{Source}

National Cancer Institute. Round Epithelial Cell Count. NCI Thesaurus. Code C74698.

The determination of the number of round epithelial cells present in a urine sample. 